\title{
Clinical Outcomes and Experience of a Multiyear Consecutive Case Series of Total Knee Arthroplasty Procedures Conducted with a Bipolar Sealer System for Hemostasis
}

\author{
Alexander P. Sah, $\mathrm{MD}^{1 \odot}$ \\ ${ }^{1}$ Sah Orthopaedic Associates, Institute for Joint Restoration, Center \\ for Joint Replacement Bldg, Fremont, California \\ J Knee Surg 2022;35:1378-1384.
}

\begin{abstract}
Address for correspondence Alexander P. Sah, MD, Sah Orthopaedic Associates, Institute for Joint Restoration, Center for Joint Replacement Bldg, 2000 Mowry Avenue, Fremont, CA 94538 (e-mail: asah@sahortho.com).
\end{abstract}

\begin{abstract}
Maximizing hemostasis during total knee replacement procedures remains a key challenge in current practice. Bipolar sealer technology achieves intraoperative hemostasis through tissue sealing and coagulation with adjustable radio frequency energy and a saline-irrigated tip. Optimal surgical site hemostasis is important to avoid potential complications such as hemarthrosis, wound drainage, increased pain, delayed discharge, and readmissions. The aim of this study is to evaluate the safety and effectiveness of the bipolar sealer device in primary knee replacement in the largest consecutive series to date. A consecutive, treatment-control series of subjects who underwent a primary total knee arthroplasty (TKA) utilizing a bipolar sealer for hemostasis, one subgroup with concomitant tranexamic acid (TXA) administration ( $n=1599)$ and one subgroup without TXA administration $(n=3582)$, compared with a control group of primary TKA under tourniquet only $(n=667)$. Statistical analyses were performed through two-tailed unpaired $t$-tests. There was less total postoperative drain output and a lower overall transfusion rate in the bipolar sealer group $(807 \mathrm{ml} \pm 428)$ $(2.5 \%)$ than the tourniquet only group $(1290 \pm 658, p=0.001)(8.4 \%, p=0.0001)$, respectively. Drainage output in bipolar sealer + TXA $(450 \pm 297 \mathrm{ml})$ was lower than the other two groups (bipolar sealer $807 \pm 428 \mathrm{~mL}, p=0.0001$; tourniquet only $1290 \pm 658 \mathrm{ml}, p=0.0001)$. The bipolar sealer group had a higher hematocrit at postoperative day 1 (POD1) (bipolar sealer: $33.1 \pm 4.3 \mathrm{cc}$, tourniquet only: $32.5 \pm 4.3 \mathrm{cc}, p=0.001$ ) and at discharge (POD2, bipolar sealer: $31.5 \pm 3.7 \mathrm{cc}$, tourniquet only: $30.2 \pm 3.9 \mathrm{cc}, p=0.0001)$. There were zero reported serious adverse events related to hemostasis management in any group. The bipolar sealer system is a safe and effective instrument to achieve intraoperative hemostasis during primary TKA. The

Keywords

- knee arthroplasty

- hemostasis

- blood transfusion

- bipolar sealer

- blood loss bipolar sealer group required significantly fewer postoperative blood product transfusions and maintained a higher hematocrit concentration at the time of discharge compared with subjects treated solely with tourniquet mediated hemostasis. Addition of TXA to local hemostasis methods may further reduce blood loss and transfusion requirements.

Level of Evidence This is a Level III study.
\end{abstract}

received

October 23, 2020

accepted after revision

January 2, 2021

published online

February 19, 2021 (c) 2021. Thieme. All rights reserved.

Thieme Medical Publishers, Inc., 333 Seventh Avenue, 18th Floor, New York, NY 10001, USA
DOI https://doi.org/

10.1055/s-0041-1723972. ISSN $1538-8506$. 
The widespread increase in obesity and rising average life expectancy within the United States have significantly contributed to the proliferation of symptomatic knee osteoarthritis that is refractory to nonoperative treatment modalities. ${ }^{1}$ As a result, there are currently over 500,000 primary total knee arthroplasty (TKA) procedures performed every year in the United States with future projections estimating well over 3 million procedures per year by $2030 .^{2,3}$ As successful as TKA can be, one of the major challenges around surgery has been blood management. Blood loss during this procedure has been associated with complications including wound drainage, infection, hypotension, dizziness, need for transfusion, delayed discharge, and increased morbidity. Blood management techniques have evolved from autologous and cell-saving transfusions, erythropoietin and iron supplementation, topical and system hemostatic agents, surgical technologies, and others. In spite of all of these developments, optimization of blood management around elective TKA remains a challenge.

Maximizing hemostasis during TKA procedures remains a key challenge in current practice, especially in the setting of increasingly medically complex patient populations. Currently, over $80 \%$ of patients who undergo TKA have a metabolic comorbidity that may affect intraoperative hemostasis or postoperative tissue remodeling. ${ }^{4}$ These patients often require significant additional care during the surgical procedure, including blood transfusion care. While every effort is made to avoid perioperative blood transfusions, which are costly, invasive, and include long-term risk to the patient, $\sim 30$ to $40 \%$ of both historic and contemporary at-risk patients undergoing TKA can require a transfusion. ${ }^{5-7}$ Additional risk factors for perioperative blood transfusions include preoperative hemoglobin levels, ${ }^{8}$ gender, and total time a tourniquet is used during the surgery. ${ }^{9}$ Blood transfusions impart high direct and indirect costs to the patient, ${ }^{10}$ along with risks of disease, infection, and surgical complications. ${ }^{11}$ Blood management is also increasingly more important as outpatient joint replacement increases, as these patients do not have the monitoring or hospital care after surgery if symptoms from blood loss should occur. Because there is no consensus on a single treatment to prevent blood loss and transfusions, understanding all possible options broadens the hemostasis armamentarium. Blood management strategies must be optimized beginning prior to entering the operating room, to assure successful outpatient outcomes and avoid readmissions.

Efforts to avoid an intraoperative blood transfusion can begin prior to the surgery taking place. Patients can be prescribed iron supplements or erythropoietin to increase their preoperative hemoglobin levels. ${ }^{12}$ Numerous intraoperative blood management strategies (strict preservation of normothermia, normovolemic hemodilution, perioperative red cell salvage, topical fibrin sealant application, and tranexamic acid (TXA) administration) are used to control bleeding and minimize the need for allogenic blood transfusion secondary to critical anemia. ${ }^{13-16}$ However, one of the most widely-used methods for intraoperative hemostasis continues to be the use of an air tourniquet. ${ }^{17}$ Although air tourniquet usage has been shown to be an effective and reliable strategy to slow blood loss during TKA, there have been reports of increased perioperative total blood loss and increased perioperative complication rates (nerve injury, deep vein thrombosis, delayed wound healing/ infection, compartment syndrome) after its utilization., ${ }^{9,21}$ Hypotensive anesthesia can also be an effective means of minimizing blood loss during TKA, ${ }^{22}$ but the technique is challenging, dependent on the expertise of the surgical staff, and not appropriate for large subpopulations of patients. ${ }^{23} \mathrm{Cell}$ salvage techniques (where the patient's own blood is collected during the surgery, filtered for contaminants, an anticoagulant is added, and returned to the patient) are successful at mitigating many of the risks that accompany traditional allogenic transfusions, but are exceptionally costly and can be wasteful if the salvaged blood is not needed. ${ }^{24}$ Topical sealants are also an option with a meta-analysis in 2014 demonstrating reductions in blood loss, length of hospital stay, and postoperative complications, ${ }^{25}$ but the products are expensive, and the small improvements in outcomes do not warrant the current market price. ${ }^{26}$

Bipolar sealer technology is an alternative method to achieve intraoperative hemostasis through tissue sealing and coagulation with adjustable radio frequency energy and a saline-irrigated tip. The combination of radio frequency energy and saline irrigation was designed to maximize hemostatic sealing without tissue searing. It has been utilized in total hip and knee arthroplasty procedures, along with numerous neurosurgical, orthopaedic, hepatobiliary, and thoracic surgical applications with successful outcomes. ${ }^{27-37}$ While there are cost considerations to adoption of the bipolar sealer technique, ${ }^{38}$ one analysis by Kuznietsova and Woodward demonstrated that the initial costs associated with establishing the procedure in a new facility or practice are recouped by the cost savings by year 3 of implementing the bipolar sealer technique. ${ }^{39}$ The extra expense of the bipolar sealer technique was also found by Ackerman et al to be offset by the cost savings due to shortened hospital stays and reduced operating room costs, resulting in a comparable cost per patient as traditional intraoperative hemostatic techniques. The benefits of bipolar sealer technology have been reported to include improved perioperative visual field ${ }^{40}$ decreased trauma to the surrounding tissue, and reduced blood loss that results in a reduced rate of transfusion. ${ }^{29,36,41,42}$

The purpose of this study is to evaluate the safety and effectiveness of the bipolar sealer device in primary knee replacement in the largest series to date. This was evaluated through a consecutive, treatment-control series of subjects who underwent a primary TKA utilizing a bipolar sealer for hemostasis as compared with those without. Several metrics were used to investigate the effectiveness of each modality including serial hematocrit values, perioperative transfusion rates, and total knee drain outputs. Safety was investigated through an evaluation of postoperative complication rates.

\section{Methods}

An observational, single site, consecutive treatment-control series was conducted for subjects who underwent primary, unilateral, cemented, TKA. An institutional database of two 
fellowship trained arthroplasty surgeons included 5,318 subjects who underwent 5,848 consecutive primary TKAs from 2004 to 2016. All subjects were diagnosed with advanced degenerative osteoarthritis and failed nonoperative treatment modalities prior to surgical reconstruction. There were 667 TKAs in the control group (group 1), 3,582 TKAs with use of a bipolar sealer (Aquamantys, Medtronic, Minneapolis, MN) without administration of TXA (group 2), and 1599 TKAs with bipolar sealer and concomitant intravenous TXA administration (group 3).

The control group contained 614 subjects who underwent 667 primary TKAs under tourniquet without the use of a bipolar sealer. All groups underwent intra-articular placement of reinfusion drains and postoperative anticoagulation with either coumadin (2 weeks) or aspirin (6 weeks) based on surgeon preference. Standard electrocautery was used for surgical approach only in all groups. All procedures were performed under tourniquet. Because tourniquet was used, there was zero intraoperative blood loss recorded. Knee blood loss was measured by knee drain output.

The study group was comprised of group 2, 3,582 TKAs in 3,241 patients, where the bipolar device was used without TXA. The subsequent 1,599 TKAs in 1,463 patients had the bipolar device used in conjunction with $1 \mathrm{~g}$ of intravenous TXA intraoperatively. The bipolar sealer was used after meniscal removal in the medial and lateral gutters, prior to definitive implant insertion with the knee in flexion in the posterior capsule, and prior to tourniquet deflation in the suprapatellar pouch.

Several metrics were collected for both groups including intraoperative tourniquet time, total knee drainage output, preoperative hematocrit, hematocrit obtained immediately (within the post-anesthesia care unit) postoperatively, hematocrit at the time of discharge, need for perioperative blood transfusion, and occurrence of postoperative paresthesias in the ipsilateral surgical extremity. Hematocrit value was measured and compared between groups because clinical intervention, such as transfusion triggers, was based on hematocrit value. Transfusions were performed if patient had clinical signs of hypotension such as lightheadedness, dizziness, hypotension, or tachycardia. Statistical analyses were performed through two-tailed unpaired $t$-tests. Data are reported as mean \pm standard deviation with significance defined as $p<0.05$.

\section{Results}

Demographics (gender, body mass index, and age) were similar among the three groups ( $\mathbf{- T a b l e s} \mathbf{1 - 3}$ ). Average intraoperative tourniquet time was also similar between the two main groups (bipolar sealer: $59.6 \pm 15.7$ minutes, tourniquet only: $58.9 \pm 15.8$ minutes, $p>0.05$; - Table 4 ). Lateral release, which is a potential source of additional bleeding, had a rate across groups that was also similar (bipolar sealer: 322 [9\%], tourniquet only: 56 [10\%], $p>0.05$; - Table 4). There was no difference in blood loss prior to discharge based on drain output or hematocrit based on anticoagulation type used. There was significantly less total postoperative drain output in the bipolar sealer group $(807 \mathrm{~mL} \pm 428)$ than the tourniquet
Table 1 Demographics of TKA surgeries with bipolar sealers or tourniquet only

\begin{tabular}{|l|l|l|l|}
\hline & $\begin{array}{l}\text { Bipolar } \\
\text { sealer }\end{array}$ & $\begin{array}{l}\text { Tourniquet } \\
\text { only }\end{array}$ & $p$-Value \\
\hline Females & $2006(56 \%)$ & $394(59 \%)$ & 0.15 \\
\hline Weight (Ibs) & $186 \pm 58$ & $190 \pm 68$ & 0.11 \\
\hline Height (in) & $67 \pm 7.3$ & $66.4 \pm 9.1$ & 0.06 \\
\hline Age (y) & $68.5 \pm 12$ & $67.5 \pm 15$ & 0.06 \\
\hline $\begin{array}{l}\text { Total number } \\
\text { of TKA }\end{array}$ & 3582 & 667 & \\
\hline
\end{tabular}

Abbreviation: TKA, total knee arthroplasty.

Table 2 Demographics of TKA surgeries with bipolar sealers or bipolar sealers and TXA administration

\begin{tabular}{|l|l|l|l|}
\hline & $\begin{array}{l}\text { Bipolar } \\
\text { sealer }\end{array}$ & $\begin{array}{l}\text { Bipolar sealer } \\
\text { and TXA }\end{array}$ & $p$-Value \\
\hline Females & $2006(56 \%)$ & $927(58 \%)$ & 0.19 \\
\hline Weight (Ibs) & $186 \pm 58$ & $188.2 \pm 42$ & 0.17 \\
\hline Height (in) & $67 \pm 7.3$ & $66.8 \pm 7.1$ & 0.36 \\
\hline Age (y) & $68.5 \pm 12$ & $68.7 \pm 14$ & 0.60 \\
\hline $\begin{array}{l}\text { Total number } \\
\text { of TKA }\end{array}$ & 3582 & 1599 & \\
\hline
\end{tabular}

Abbreviations: TKA, total knee arthroplasty; TXA, tranexamic acid.

Table 3 Demographics of TKA surgeries with bipolar sealers and TXA administration or tourniquet only

\begin{tabular}{|l|l|l|l|}
\hline & $\begin{array}{l}\text { Bipolar sealer } \\
\text { and TXA }\end{array}$ & $\begin{array}{l}\text { Tourniquet } \\
\text { only }\end{array}$ & $p$-Value \\
\hline Females & $927(58 \%)$ & $394(59 \%)$ & 0.64 \\
\hline Weight (lbs) & $188.2 \pm 42$ & $190 \pm 68$ & 0.44 \\
\hline Height (in) & $66.8 \pm 7.1$ & $66.4 \pm 9.1$ & 0.26 \\
\hline Age (y) & $68.7 \pm 14$ & $67.5 \pm 15$ & 0.07 \\
\hline $\begin{array}{l}\text { Total number } \\
\text { of TKA }\end{array}$ & 1599 & 667 & \\
\hline
\end{tabular}

Abbreviations: TKA, total knee arthroplasty; TXA, tranexamic acid.

only group $(1,290 \pm 658, p=0.001 ;-$ Table 4$)$. There was less drainage output in group $3(450 \pm 297 \mathrm{ml})$ compared with either of the other two groups (bipolar sealer $807 \pm 428 \mathrm{~mL}$, $p=0.0001$; - Table 5 and tourniquet only $1,290 \pm 658 \mathrm{~mL}$, $p=0.0001 ;$ - Table 6 ). As a result, there was a lower overall transfusion rate in the bipolar sealer group (89, 2.5\%) than in subjects who underwent tourniquet only TKA $(56,8.4 \%$, $p=0.0001$; - Table 4). There was also further reduction in group $3(19,1.2 \% p=0.002$ and 0.0 .0001 as compared with the bipolar and tourniquet only groups respectively; - Tables 5 and 6). Hematocrit was similar between groups at baseline (bipolar sealer: $40.4 \pm 3.4 \mathrm{cc}$, tourniquet only: $40.2 \pm 4.1 \mathrm{cc}$, $p>0.05$; - Table 4) and immediately postoperatively (bipolar sealer: $34.9 \pm 3.2 \mathrm{cc}$, tourniquet only: $35 \pm 3.7 \mathrm{cc}, p>0.05$; -Table 4). However, the bipolar sealer group had a higher hematocrit at postoperative day 1 (bipolar sealer: $33.1 \pm 4.3 \mathrm{cc}$, 
Table 4 Surgical data of TKA surgeries with bipolar sealers or tourniquet only

\begin{tabular}{|l|l|l|l|}
\hline & $\begin{array}{l}\text { Bipolar } \\
\text { sealer }\end{array}$ & $\begin{array}{l}\text { Tourniquet } \\
\text { only }\end{array}$ & $p$-Value \\
\hline $\begin{array}{l}\text { Ave tourniquet } \\
\text { time (min) }\end{array}$ & $59.6 \pm 15.7$ & $58.9 \pm 15.8$ & 0.3 \\
\hline $\begin{array}{l}\text { Total knee } \\
\text { drainage } \\
\text { output (mL) }\end{array}$ & $807 \pm 428$ & $1290 \pm 658$ & $0.001^{* *}$ \\
\hline $\begin{array}{l}\text { Hematocrit, } \\
\text { preoperative }\end{array}$ & $40.4 \pm 3.4$ & $40.2 \pm 4.1$ & 0.18 \\
\hline $\begin{array}{l}\text { Hematocrit, } \\
\text { PACU }\end{array}$ & $34.9 \pm 3.2$ & $35 \pm 3.7$ & 0.47 \\
\hline $\begin{array}{l}\text { Hematocrit, } \\
\text { postoperative } \\
\text { day 1 }\end{array}$ & $33.1 \pm 4.3$ & $32.5 \pm 4.3$ & $0.001^{* *}$ \\
\hline $\begin{array}{l}\text { Hematocrit, } \\
\text { postoperative } \\
\text { day 2 }\end{array}$ & $31.5 \pm 3.7$ & $30.2 \pm 3.9$ & $0.0001^{* * *}$ \\
\hline Transfusion rate & $89(2.5 \%)$ & $56(8.4 \%)$ & $0.0001^{* * *}$ \\
\hline $\begin{array}{l}\text { Postoperative } \\
\text { paresthesias }\end{array}$ & $11(0.31 \%)$ & $1(0.15 \%)$ & 0.7 \\
\hline Lateral releases & $322(9 \%)$ & $56(10 \%)$ & 0.66 \\
\hline
\end{tabular}

Abbreviations: PACU, postanesthesia care unit; TKA, total knee arthroplasty.

Table 5 Surgical data of TKA surgeries with bipolar sealers or bipolar sealers and TXA administration

\begin{tabular}{|l|l|l|l|}
\hline & $\begin{array}{l}\text { Bipolar } \\
\text { sealer }\end{array}$ & $\begin{array}{l}\text { Bipolar sealer } \\
\text { and TXA }\end{array}$ & $p$-Value \\
\hline $\begin{array}{l}\text { Ave tourniquet } \\
\text { time (min) }\end{array}$ & $59.6 \pm 15.7$ & $60.2 \pm 16.2$ & 0.21 \\
\hline $\begin{array}{l}\text { Total knee } \\
\text { drainage } \\
\text { output (mL) }\end{array}$ & $807 \pm 428$ & $450 \pm 297$ & $0.0001^{* * *}$ \\
\hline $\begin{array}{l}\text { Hematocrit, } \\
\text { preoperative }\end{array}$ & $40.4 \pm 3.4$ & $40.5 \pm 4.8$ & 0.39 \\
\hline $\begin{array}{l}\text { Hematocrit, } \\
\text { PACU }\end{array}$ & $34.9 \pm 3.2$ & $35.1 \pm 4.1$ & 0.06 \\
\hline $\begin{array}{l}\text { Hematocrit, } \\
\text { postoperative } \\
\text { day 1 }\end{array}$ & $33.1 \pm 4.3$ & $34.5 \pm 4.1$ & $0.0001^{* * *}$ \\
\hline $\begin{array}{l}\text { Hematocrit, } \\
\text { postoperative } \\
\text { day 2 }\end{array}$ & $31.5 \pm 3.7$ & $32.8 \pm 3.5$ & $0.0001^{* * *}$ \\
\hline Transfusion rate & $89(2.5 \%)$ & $19(1.2 \%)$ & $0.002^{* *}$ \\
\hline $\begin{array}{l}\text { Postoperative } \\
\text { paresthesias }\end{array}$ & $11(0.31 \%)$ & $1(0.06 \%)$ & 0.12 \\
\hline Lateral releases & $322(9 \%)$ & $127(7.9 \%)$ & 0.24 \\
\hline
\end{tabular}

Abbreviations: PACU, postanesthesia care unit; TKA, total knee arthroplasty; TXA, tranexamic acid.

tourniquet only: $32.5 \pm 4.3 \mathrm{cc}, p=0.001$; - Table 4 ) and at time of discharge (postoperative day 2, bipolar sealer: $31.5 \pm 3.7 \mathrm{cc}$, tourniquet only: $30.2 \pm 3.9 \mathrm{cc}, p=0.0001$; - Table 4 ).

Unexplained postoperative paresthesias occurred less frequently in knees without $(1,0.15 \%)$ versus knees with
Table 6 Surgical data of TKA surgeries with bipolar sealers and TXA administration or tourniquet only

\begin{tabular}{|l|l|l|l|}
\hline & $\begin{array}{l}\text { Bipolar sealer } \\
\text { and TXA }\end{array}$ & $\begin{array}{l}\text { Tourniquet } \\
\text { only }\end{array}$ & $p$-Value \\
\hline $\begin{array}{l}\text { Ave tourniquet } \\
\text { time (min) }\end{array}$ & $60.2 \pm 16.2$ & $58.9 \pm 15.8$ & 0.08 \\
\hline $\begin{array}{l}\text { Total knee } \\
\text { drainage } \\
\text { output (mL) }\end{array}$ & $450 \pm 297$ & $1290 \pm 658$ & $0.0001^{* * *}$ \\
\hline $\begin{array}{l}\text { Hematocrit, } \\
\text { preoperative }\end{array}$ & $40.5 \pm 4.8$ & $40.2 \pm 4.1$ & 0.16 \\
\hline $\begin{array}{l}\text { Hematocrit, } \\
\text { PACU }\end{array}$ & $35.1 \pm 4.1$ & $35 \pm 3.7$ & 0.59 \\
\hline $\begin{array}{l}\text { Hematocrit, } \\
\text { postoperative } \\
\text { day 1 }\end{array}$ & $34.5 \pm 4.1$ & $32.5 \pm 4.3$ & $0.0001^{* * *}$ \\
\hline $\begin{array}{l}\text { Hematocrit, } \\
\text { postoperative } \\
\text { day 2 }\end{array}$ & $32.8 \pm 3.5$ & $30.2 \pm 3.9$ & $0.001^{* * *}$ \\
\hline Transfusion rate & $19(1.2 \%)$ & $56(8.4 \%)$ & $0.0001^{* * *}$ \\
\hline $\begin{array}{l}\text { Postoperative } \\
\text { paresthesias }\end{array}$ & $1(0.06 \%)$ & $1(0.15 \%)$ & 0.5 \\
\hline Lateral releases & $127(7.9 \%)$ & $56(10 \%)$ & 0.73 \\
\hline
\end{tabular}

Abbreviations: PACU, postanesthesia care unit; TKA, total knee arthroplasty; TXA, tranexamic acid.

the use of a bipolar sealer $(10,0.31 \%, p=0.4$, - Table 4$)$. There were zero reported serious adverse events in both groups.

\section{Discussion}

This study demonstrates that the bipolar sealer system is a safe and effective instrument to achieve intraoperative hemostasis during a primary TKA. The bipolar sealer group required significantly fewer postoperative blood product transfusions and maintained a higher hematocrit concentration at the time of discharge compared with subjects treated solely with tourniquet-mediated hemostasis. Furthermore, there was no difference in observed cases of postoperative paresthesias in subjects treated with the bipolar sealer system compared with those who underwent primary TKA under tourniquet. The addition of TXA can further reduce blood loss based on drain output and hematocrit decreased blood loss. Transfusions are also less frequent when the two treatment options are used together.

Multiple investigations of total joint replacement procedures have reported reductions in postoperative blood loss or transfusions using a saline-coupled bipolar sealing device compared with conventional technologies. ${ }^{43-46}$ Isabell and Weeden evaluated subjects undergoing primary unilateral TKA procedures using conventional electrocautery to the same procedure using bipolar sealer technologies. They reported a significant reduction in autologous (16 vs. $44 \%$, $p<0.001$ ) and allogeneic ( 8 vs. $22 \%, p<0.001$ ) transfusion requirements in the bipolar sealer group. ${ }^{43}$ Similarly, Marulanda et al reported a significantly lower transfusion 
rate in subjects treated with a bipolar sealer device (20\%) during unilateral, anterior total hip arthroplasty (THA) than in those treated with conventional electrocautery (52\%). ${ }^{44}$ Pfeiffer et al demonstrated the use of a bipolar sealer resulted $28.4 \%$ reduction in blood loss and reduced the rate of transfusions by a factor of five when compared with procedures without the bipolar sealer. ${ }^{45}$ Additionally, Morris et al reported that the use of a bipolar sealer device in anterior supine intermuscular THA resulted in fewer intraoperative and postoperative transfusions than procedures employing standard electrocautery techniques. ${ }^{47}$ Although these trends are consistent with our findings, the observed transfusion rate in both arms of our study was lower than previously reported values after a primary unilateral joint replacement. Perhaps this is a result of institutional policies within our study center to initiate blood transfusion protocols based on observable symptoms rather than laboratory values, or possibly it is secondary to our adoption of efficient and less invasive surgical approaches. With the volume of outpatient joint replacement procedures increasing $47 \%$ from 2012 to 2015 and the majority of joint replacement procedures expected to be performed in an outpatient setting by $2026,{ }^{48}$ blood management and precise hemostasis techniques will play a critical role in minimizing blood loss, anemia, and other complications from hypotension, fainting, or transfusion associated with rapid discharges. This bipolar device could be critical to assuring patient safety and increasing the reliability of outpatient joint replacement.

Conversely, other well-designed studies have reported little to no evidence that bipolar sealing devices are superior to conventional electrocautery. Falez et al reported there was no difference in perioperative blood loss either on the day of surgery or 3 days after surgery between subjects randomized to parallel operative groups utilizing either a bipolar sealer or standard electrocautery. ${ }^{49}$ Nielsen et al conducted a prospective cohort study with retrospective controls undergoing revision TKA without the use of a tourniquet. ${ }^{50}$ They reported no significant differences in calculated blood loss between the prospective bipolar sealer group and the retrospective standard electrocautery group. Morris et al, Zeh et al, and Barsoum et al published separate prospective, double-blind studies that found no difference in transfusion requirements between bipolar sealer treated individuals undergoing THA and subjects randomized toTHA with standard electrocautery. ${ }^{51,52}$ Further, a meta-analysis by Yang et al of studies comparing standard electrocautery to bipolar sealers found no significant difference in the quantity of blood loss, hemoglobin levels, length of hospital stay, or operation time between the two devices. ${ }^{53}$ Similarly, meta-analysis evidence from Min et al reviewing randomized controlled trials suggested that usage of the bipolar sealer reduced the need for transfusions, but had no impact on hemoglobin drop, blood loss, Harris score, and rates of infection. $^{54}$

\section{Bipolar Sealer Used with TXA}

Measurable outcomes such as subjective patient recovery, decreased length of inpatient hospital admission, and a diminished blood product transfusion rate have been stressed within the current climate of healthcare quality evaluations. The effect of emerging surgical approaches and technologies on blood transfusion rates is of particular importance given the potentially serious adverse effects (infection, depression of erythropoiesis, acute lung injury, anaphylactic hypotensive reactions, graft versus host disease) associated with allogenic product transfusion. ${ }^{55}$ As a result, several intraoperative blood conservation adjuncts have been utilized and previously studied. One well-studied hemostatic agent is TXA, which inhibits fibrinolysis leading to improved effectiveness of coagulation and hemostasis. The clinical randomization of an antifibrinolytic in significant hemorrhage 2 (CRASH-2) trial demonstrated that administration of TXA significantly reduced the rate of mortality, vascular occlusive events, and blood transfusion in trauma patients with significant hemorrhage. ${ }^{56}$ TXA administration also has been shown to significantly decrease intraoperative bleeding in patients undergoing elective gynecologic, cardiac, and some orthopaedic surgeries. ${ }^{57}$ While additional confirmation studies are underway, evidence suggests that TXA and bipolar sealants can be used in the same patient as they have different mechanisms of action, whereas TXA stabilizes a clot and prevents its breakdown and dissolution, the bipolar sealer encourages coagulation and shrinks collagen tissues to achieve hemostasis. ${ }^{58}$ Fibrin sealants (Evicel/Floseal) are alternative agents that have been shown to provide excellent hemostasis. ${ }^{59}$ However, although these sealants are efficacious, they are expensive and carry antigenic risks. $^{60}$

The bipolar device may be helpful in tourniquetless total knee surgery. There are many rare, yet potentially life- or limbthreatening complications that have been reported after air tourniquet utilization to create a bloodless field during TKA procedures. These risks include neurologic injury, muscle crush injuries, pulmonary emboli, and arterial compromise (secondary to traction injuries, fractures of atherosclerotic plaques, intimal tears, thrombosis or prolonged vessel occlusions). ${ }^{61-63}$ Patients with a history of arterial insufficiency, a suspected popliteal artery aneurysm, or radiographic evidence of superficial femoral or popliteal artery calcifications, have been shown to be at higher risk of these potentially limbthreatening sequelae of tourniquet use. ${ }^{63}$ Utilization of a bipolar sealer system over an air tourniquet during primary TKA procedures should be considered to reduce the risk of these devastating complications without adversely impacting hemostasis.

A limitation of this study is the single-site design, which limits generalizability of the results. All procedures were performed by fellowship-trained surgeons at a high-volume, specialized orthopaedic medical center. Similar results may not be observed in a setting with less-experienced healthcare providers and staff. Second, intraoperative and perioperative blood loss was inferred based on postoperative hemoglobin concentration decrements, drain outputs, and transfusion requirements rather than direct measurements. Nevertheless, while previous studies have evaluated patients in the hundreds, this study is the largest to date in evaluating thousands of consecutive patients with these hemostasis methods, so we believe that the results are of value to surgeons 
considering using the technology. Furthermore, the statistically and clinically relevant improvements in transfusion requirements after a bipolar sealer system was utilized to achieve intraoperative hemostasis establish a significant advantage compared with tourniquet only techniques.

Despite limitations, this study remains the largest series to date to investigate bipolar sealer utilization to minimize intraoperative blood loss during primary TKAs. In combination with the other recognized clinical benefits of this technology (limited tissue searing, minimal learning curve), our results support that bipolar sealer systems are a safe and effective blood management alternative to air tourniquet systems during primary TKA procedures. Improved intraoperative hemostasis may potentially lead to a reduction in postoperative hemarthrosis and time to return to function. Therefore, future studies should investigate patient-reported outcome measures to describe the impacts of saline coupled bipolar sealer use on postoperative pain, swelling, and quality of life.

\section{Ethical Approval}

This work was exempt from IRB approval.

Note

Surgical treatments, data collection, and data analysis were performed at Sah Orthopaedic Associates Institute for Joint Restoration.

\section{Funding}

Database support for this study was provided by Medtronic.

\section{Conflict of Interest}

A.P.S. is on speaker's bureau and writing grant for this study was provided by Medtronic.

\section{References}

1 Elders MJ. The increasing impact of arthritis on public health. J Rheumatol Suppl 2000;60:6-8

2 Kurtz S, Ong K, Lau E, Mowat F, Halpern M. Projections of primary and revision hip and knee arthroplasty in the United States from 2005 to 2030. J Bone Joint Surg Am 2007;89(04):780-785

3 Losina E, Walensky RP, Kessler CL, et al. Cost-effectiveness of total knee arthroplasty in the United States: patient risk and hospital volume. Arch Intern Med 2009;169(12):1113-1121, discussion 1121-1122

4 Parks ML. CORR insights: comorbidities in patients undergoing total knee arthroplasty: do they influence hospital costs and length of stay? Clin Orthop Relat Res 2014;472(12):3951-3952

5 Bierbaum B, Callaghan J, Galante J, Rubash H, Tooms R, Welch RB. An analysis of blood management in patients having a total hip or knee arthroplasty. J Bone Jt Surg Am. 1999;81:2-10

6 Robinson S, McGonigle O, Volin S, et al. Comprehensive look at blood transfusion utilization in total joint arthroplasty at a single academic medical center under a single surgeon. J Blood Transfus 2013;2013:983250

7 Meybohm P, Kohlhof H, Wirtz DC, et al. Preoperative anaemia in primary hip and knee arthroplasty. Z Orthop Unfall 2020;158 (02):194-200

8 Boutsiadis A, Reynolds RJ, Saffarini M, Panisset JC. Factors that influence blood loss and need for transfusion following total knee arthroplasty. Ann Transl Med 2017;5(21):418
9 Prasad N, Padmanabhan V, Mullaji A. Blood loss in total knee arthroplasty: an analysis of risk factors. Int Orthop 2007;31(01): 39-44

10 Nichols CI, Vose JG. Clinical outcomes and costs within 90 days of primary or revision total joint arthroplasty. J Arthroplasty 2016; 31(07):1400-1406.e3

11 Goodnough LT, Shuck JM. Risks, options, and informed consent for blood transfusion in elective surgery. Am J Surg 1990;159(06): 602-609

12 Lu Q Peng H, Zhou GJ, Yin D. Perioperative blood management strategies for total knee arthroplasty. Orthop Surg 2018;10(01): 8-16

13 Guild GN III, Runner RP, Castilleja GM, Smith MJ, Vu CL. Efficacy of hybrid plasma scalpel in reducing blood loss and transfusions in direct anterior total hip arthroplasty. J Arthroplasty 2017;32(02): 458-462

14 Liu D, Dan M, Martinez Martos S, Beller E. Blood management strategies in total knee arthroplasty. Knee Surg Relat Res 2016;28 (03):179-187

15 Rosenthal BD, Haughom BD, Levine BR. A retrospective analysis of hemostatic techniques in primary total knee arthroplasty: traditional electrocautery, bipolar sealer, and argon beam coagulation. Am J Orthop 2016;45(04):E187-E191

16 Ulrich SD, Kyle B, Johnson AJ, Zywiel MG, Mont MA. Strategies to reduce blood loss in lower extremity total joint arthroplasty. Surg Technol Int 2010;20:341-347

17 Berry DJ, Bozic KJ. Current practice patterns in primary hip and knee arthroplasty among members of the American Association of Hip and Knee Surgeons. J Arthroplasty 2010;25(6, Suppl):2-4

18 Hernandez AJ, Almeida AM, Fávaro E, Sguizzato GT. The influence of tourniquet use and operative time on the incidence of deep vein thrombosis in total knee arthroplasty. Clinics (São Paulo) 2012;67 (09):1053-1057

19 Olivecrona C, Blomfeldt R, Ponzer S, Stanford BR, Nilsson BY. Tourniquet cuff pressure and nerve injury in knee arthroplasty in a bloodless field: a neurophysiological study. Acta Orthop 2013;84(02):159-164

20 Olivecrona C, Lapidus LJ, Benson L, Blomfeldt R. Tourniquet time affects postoperative complications after knee arthroplasty. Int Orthop 2013;37(05):827-832

21 Tie K, Hu D, Qi Y, Wang H, Chen L. Effects of tourniquet release on total knee arthroplasty. Orthopedics 2016;39(04):e642-e650

22 Jiang J, Yue Y, Li B, Zhou R. Deliberate hypotension for orthopaedic surgery. Cochrane Database Syst Rev 2017

23 Aken H. Deliberated hypotension. In: Miller's Anesthesia, R. Miller, ed.Tokyo: Churchill Livingstone; 2000:1470-1486

24 Kuppurao L, Wee M. Perioperative cell salvage. Contin Educ Anaesth Crit Care Pain 2010;10:104-108

25 Wang H, Shan L, Zeng H, Sun M, Hua Y, Cai Z. Is fibrin sealant effective and safe in total knee arthroplasty? A meta-analysis of randomized trials. J Orthop Surg Res 2014;9:36

26 Steuten L, Vallejo-Torres L, Bastide P, Buxton M. Analysing uncertainty around costs of innovative medical technologies: the case of fibrin sealant (QUIXIL) for total knee replacement. Health Policy 2009;89(01):46-57

27 Caruana EJ, Kadlec J, Iyer S, Mani A, Solli P, Scarci M. The Aquamantys $\left({ }^{\circledR}\right)$ system improves haemostasis and pneumostasis in open decortication for thoracic empyema. J Thorac Dis 2016;8 (07):1540-1545

28 Currò G, Lazzara S, Barbera A, et al. The Aquamantys ${ }^{\circledR}$ system as alternative for parenchymal division and hemostasis in liver resection for hepatocellular carcinoma: a preliminary study. Eur Rev Med Pharmacol Sci 2014;18(2, Suppl):2-5

29 Suarez JC, Slotkin EM, Szubski CR, Barsoum WK, Patel PD. Prospective, randomized trial to evaluate efficacy of a bipolar sealer in direct anterior approach total hip arthroplasty. J Arthroplasty 2015;30(11):1953-1958 
30 Derman PB, Kamath AF, Lee G-C. Saline-coupled bipolar sealing in revision total knee arthroplasty for infection. Am J Orthop 2013; 42(09):407-411

31 Frank SM, Wasey JO, Dwyer IM, Gokaslan ZL, Ness PM, Kebaish KM. Radiofrequency bipolar hemostatic sealer reduces blood loss, transfusion requirements, and cost for patients undergoing multilevel spinal fusion surgery: a case control study. J Orthop Surg Res 2014;9:50

32 Fukui D, Kawakami M, Nakao SI, et al. Reduced blood loss and operation time in lumbar posterolateral fusion using a bipolar sealer. Eur Spine J 2017;26(03):726-732

33 Grasso G, Giambartino F, Iacopino DG. Hemostasis in brain tumor surgery using the Aquamantys system. Med Sci Monit 2014; 20:538-543

34 Huang Z, Ma J, Shen B, et al. Use of a bipolar blood-sealing system during total joint arthroplasty. Orthopedics 2015;38(12):757-763

35 Kamath AF, Austin DC, Derman PB, Clement RC, Garino JP, Lee G-C. Saline-coupled bipolar sealing in simultaneous bilateral total knee arthroplasty. Clin Orthop Surg 2014;6(03):298-304

36 Marulanda GA, Ulrich SD, Seyler TM, Delanois RE, Mont MA. Reductions in blood loss with a bipolar sealer in total hip arthroplasty. Expert Rev Med Devices 2008;5(02):125-131

37 Plymale MF, Capogna BM, Lovy AJ, Adler ML, Hirsh DM, Kim SJ. Unipolar vs bipolar hemostasis in total knee arthroplasty: a prospective randomized trial. J Arthroplasty 2012;27(06):1133-7.e1

38 Ackerman SJ, Tapia CI, Baik R, Pivec R, Mont MA. Use of a bipolar sealer in total hip arthroplasty: medical resource use and costs using a hospital administrative database. Orthopedics 2014;37 (05):e472-e481

39 Kuznietsova V, Woodward RS. Estimating the learning curve of a novel medical device: bipolar sealer use in unilateral total knee arthroplasties. Value Health 2018;21(03):283-294

40 Saltzman BM, Oni JK. A review of bipolar sealer use in modern total joint arthroplasty. Ann. Orthop. Rheumatol. 2014k2:1015

41 Fechisin J, Scuderi G. The efficacy of bipolar transcollation in managing blood loss in total knee arthroplasty. Tech Knee Surg 2011;10:206-210

42 Wang Z, Tian A, Feng K, Wang Q Wang Y. Bipolar sealer can reduce intraoperative blood loss and transfusion in major orthopedic surgery: a meta-analysis and trial sequence analysis. 2018. Available at: https://www.oncotarget.com/article/23980/text/

43 Isabell G, Weeden S. Hemodynamic efficacy of a bipolar sealing device in primary total knee arthroplasty. In Annual Meeting of the Texas Orthopaedic Association; 2006

44 Marulanda G, Ragland P, Mont M. Use of a bipolar sealer device for hemostasis in total hip arthroplasty. In Am Acad Ortho Surg; 2006

45 Pfeiffer M, Bräutigam H, Draws D, Sigg A. A new bipolar blood sealing system embedded in perioperative strategies vs. a conventional regimen for total knee arthroplasty: results of a matchedpair study Ein neues bipolares Blutstillungssystem zur Ergänzung perioperativer herkömmlichen Verfahren. Ger Med Sci 2005;3:3-7

46 Pierson J, Hellman E, Earles D. Randomized, prospective trial to examine the hemostatic efficacy of a bipolar sealing device in TKA. In Am Acad Ortho Surg; 2006. Presented at Annual Meeting AAOS

47 Morris MJ, Barrett M, Lombardi AV Jr, Tucker TL, Berend KR. Randomized blinded study comparing a bipolar sealer and stan- dard electrocautery in reducing transfusion requirements in anterior supine intermuscular total hip arthroplasty. J Arthroplasty 2013;28(09):1614-1617

48 Bert JM, Hooper J, Moen S. Outpatient total joint arthroplasty. Curr Rev Musculoskelet Med 2017;10(04):567-574

49 Falez F, Meo A, Panegrossi G, Favetti F, La Cava F, Casella F. Blood loss reduction in cementless total hip replacement with fibrin spray or bipolar sealer: a randomised controlled trial on ninety five patients. Int Orthop 2013;37(07):1213-1217

50 Nielsen CS, Gromov K, Jans Ø, Troelsen A, Husted H. No effect of a bipolar sealer on total blood loss or blood transfusion in nonseptic revision knee arthroplasty-a prospective study with matched retrospective controls. J Arthroplasty 2017;32(01):177-182

51 Barsoum WK, Klika AK, Murray TG, Higuera C, Lee HH, Krebs VE. Prospective randomized evaluation of the need for blood transfusion during primary total hip arthroplasty with use of a bipolar sealer. J Bone Joint Surg Am 2011;93(06):513-518

52 Zeh A, Messer J, Davis J, Vasarhelyi A, Wohlrab D. The Aquamantys system-an alternative to reduce blood loss in primary total hip arthroplasty? J Arthroplasty 2010;25(07):1072-1077

53 Yang Y, Zhang LC, Xu F, Li J, Lv YM. Bipolar sealer not superior to standard electrocautery in primary total hip arthroplasty: a meta-analysis. J Orthop Surg Res 2014;9:92

54 Min J-K, Zhang Q-H, Li H-D, Li H, Guo P. The efficacy of bipolar sealer on blood loss in primary total hip arthroplasty: a metaanalysis. Medicine (Baltimore) 2016;95(19):e3435

55 Walker RH. Special report: transfusion risks. Am J Clin Pathol 1987;88(03):374-378

56 Roberts I, Shakur H, Afolabi A, et al;CRASH-2 collaborators. The importance of early treatment with tranexamic acid in bleeding trauma patients: an exploratory analysis of the CRASH-2 randomised controlled trial. Lancet 2011;377(9771):1096-1101, 1101.e1-1101.e2

57 Sekhavat L, Tabatabaii A, Dalili M, Farajkhoda T, Tafti AD. Efficacy of tranexamic acid in reducing blood loss after cesarean section. J Matern Fetal Neonatal Med 2009;22(01):72-75

58 Seviciu A, Gross I, Fathima S, Walsh SM. Effects of tranexamic acid and bipolar sealer alone or in combination in primary total knee arthroplasty: a prospective, randomized, controlled trial. Arthroplast Today 2016;2(02):77-82

59 Richter F, Schnorr D, Deger S, et al. Improvement of hemostasis in open and laparoscopically performed partial nephrectomy using a gelatin matrix-thrombin tissue sealant (FloSeal). Urology 2003; 61(01):73-77

60 Achneck HE, Sileshi B, Jamiolkowski RM, Albala DM, Shapiro ML, Lawson JH. A comprehensive review of topical hemostatic agents: efficacy and recommendations for use. Ann Surg 2010;251(02): 217-228

61 Fletcher IR, Healy TEJ. The arterial tourniquet. Ann R Coll Surg Engl 1983;65(06):409-417

62 McEwen JA. Complications of and improvements in pneumatic tourniquets used in surgery. Med Instrum 1981;15(04):253-257

63 Smith AG, Capobianco R, Cher D, et al. Open versus minimally invasive sacroiliac joint fusion: a multi-center comparison of perioperative measures and clinical outcomes. Ann Surg Innov Res 2013;7(01):14 